\title{
The Impact of Member Emotional Intelligence on Psychological Safety in Work Teams
}

\author{
Steven R. Harper \\ James Madison University \\ Charles D. White \\ Longwood University
}

\begin{abstract}
We use collective induction as a framework for examining the interaction of individual team-member's emotional intelligence in project teams. Using a sample of 108 project teams, we test the role of team member emotional intelligence in the development of psychological safety, which has been shown to improve team learning and performance. Results suggest that having individuals on the team who have above average emotional perception and emotional management improves member perceptions of psychological safety.
\end{abstract}

\section{Introduction}

The use of cross-functional work teams continues to play an increasingly important role in modern organizations. These teams bring together employees with diverse backgrounds, knowledge, and skills giving rise to a growing stream of research examining group composition and performance (Pelled, Eisenhardt, \& Xin, 1999). In addition, these teams are frequently tasked with developing innovative products, services or processes to contribute to organizational competitive advantage. As such, there is considerable interest in studying those aspects of teams that contribute to their ability to function effectively and, often, to innovate. One common way of studying teams is the input-process-output model (Gladstein, 1984; Guzzo \& Shea, 1992; Hackman, 1987; McGrath, 1964). This model seeks to understand team effectiveness by studying team inputs and processes, as well as the interactions between them, in order to understand team outputs. Team inputs include individual-level factors such as demographics and traits, group-level factors such as team size, and environmental-level factors such as reward structures.

In this study, we seek to describe how the emotional intelligence of a team's members, as a team input, influences member perceptions of psychological safety, a team process that has been shown to influence team outcomes such as team learning, innovation, and overall performance. Psychological safety is defined as a shared belief by members of a team that the team is safe for interpersonal risk taking (Edmondson, 1999). While the attitudes of the team leader have been examined as relevant antecedents to psychological safety (Nembhard \& Edmondson, 2006), we are aware of no studies that examine the attributes of team members as possible antecedents to psychological safety. We begin by reviewing the Mayer and Salovey (1997) model of emotional intelligence. We then describe psychological safety and its importance for work teams. Using collective induction (Laughlin, 1999) as a framework to describe how emotional intelligence may impact member perceptions of psychological safety, we then present and test several hypotheses relating EI, as a team input, to psychological safety.

\section{Emotional Intelligence}

Emotional intelligence is, "a type of social intelligence that involves the ability to monitor one's own and others emotions, to discriminate among them, and to use this information to guide one's thinking and actions" (Mayer \& Salovey, 1993 p. 433). The Mayer Salovey (1997) model of emotional intelligence is an ability-based model that defines emotional intelligence according to four branch skills: emotional perception, emotional facilitation, emotional understanding and emotional management. 


\section{Emotional Perception}

The first branch of the ability model of emotional intelligence is emotional perception, described as the ability to become aware of emotions in the self and in others. The concept of "others" is not limited to other individuals; it also includes the products of others (i.e., designs, music, and artwork that are produced by others), as well as products of nature (i.e., landscapes, sounds, and behaviors) (Mayer \& Salovey, 1997). Thus examples of the emotion of anger could include a painting of an enraged mob of people, or a picture of a violent thunderstorm. While emotional perception is the fundamental building block of emotional intelligence, it alone cannot cause the higher order branches to exist; emotional perception is a necessary condition but not a sufficient condition for the other branches and the whole of emotional intelligence.

To support the more psychologically-integrated processes that are manifested in the higher branches of emotional intelligence, each of the individual branches also has a developmental dimension that ranges from early-developed skills to later-developed skills. The skills of being aware of and identifying emotions in the self and others described above represent the early skills in the emotional perception branch. Latter skills that also enable the effective development of the other branches include the ability to express emotions accurately and to discriminate between real and false emotions expressed by others. We can begin to see the tools that are being developed that will enable the more integrated branches to function effectively.

\section{Emotional Facilitation}

The second branch of emotional intelligence is emotional facilitation, in which emotions are not only sensed, but they also begin to prioritize thinking and can be seen to expand and improve cognitive processing (Mayer \& Salovey, 1997). Again, the abilities in this branch are arrayed along a developmental scale from early to later. In the early stages, emotions act a signaling mechanism to alert us of inconsistencies in our environment, actions, and thoughts. For example, when lounging outside on a sunny day there may be a sense of worry that you are not completing that paper you need to write or that you are not mowing the lawn, and in this way the emotion of worry is directing your thoughts about your tan to other tasks that must be completed. Later in the development stages, an individual can imagine new situations and anticipate how they will make them feel. In this way they can play out different scenarios in their "emotional theater of the mind" (Mayer \& Salovey, 1997, p. 13) and see that they will feel better when they have completed their paper and yard work before lying in the sun to improve their tan (however, a new worry of skin damage may begin to operate).

\section{Emotional Understanding}

In the early developmental stages are the abilities to label emotions and to recognize a more varied gradation of emotions. An example here is the difference between liking someone and loving them. By being specific in the meaning of the words describing emotions, a more precise understanding of each of the emotions can result. It is also here where the cause and effect relationships between events and emotions add to knowledge. By correctly understanding that sadness is often concurrent with experiencing a loss and that anger often results from someone or something blocking your goal, the knowledge needed for correctly taking action based on these emotions is created.

Emotional understanding also includes knowing why combinations of feelings can exist simultaneously. For example, you may feel happy, and yet sad, at the same time when you learn a colleague has been given a great offer to teach at another university. You are happy that they received the offer and are progressing in their career, but you are sad since they will be leaving and you will not be able to see and interact with them as frequently. Finally, at the later development stages of emotional understanding is the ability to recognize chains of emotions and recognize which transactions are more 
likely. These chains include being surprised when you find that someone is sitting in your seats at a concert, next feeling angry that they have taken your seats, and then experiencing satisfaction when you have the usher make them move to their proper seats. Alternatively, you may feel remorse since you got angry and yelled at the people in your concert seats when they had just made an honest mistake. Knowing what the likely chains are can influence how you act in various situations.

\section{Emotional Management}

The most psychologically-integrated branch of the Mayer and Salovey (1997) conceptualization of emotional intelligence is emotional management. It is here where the behaviors of the individual are determined and thus we term this the action branch. This branch's lower developmental ability is for individuals to be open to feelings, both those that are or are not comfortable. Next is the ability to control the effect of the emotions perceived, either by engaging in the emotion or by detaching from it. An example of this is not yelling at the people who were sitting in your seats at the concert, but instead taking a deep breath. By not expressing your emotions, you begin to separate the emotion from behavior and have taken the step towards managing your emotions and not having them control you.

Later developments include reflectively monitoring emotions in oneself and in others, and being able to recognize the effects of emotions on behavior and then combining this with the lessons learned from emotional understanding, such that we can control the behaviors normally generated by these emotions, but now not through detaching from them, but rather through actually changing the emotions. The management of emotion may demand moderating the emotion, enhancing the emotion, or leaving it alone, all of which depends on which resulting behavior is desired. This can be done in oneself and in others. Examples here include a team manager bringing in donuts the day after the team lost a big account. This will reduce the feeling of sadness from failing to get the job, at least in the short term, which may be long enough to get the team involved in their next project.

Emotional intelligence has been shown to positively impact a number of workplace outcomes and there is some limited evidence (McEnrue, Groves, \& Shen, 2010) that training can improve a leader's emotional intelligence. Managers with higher emotional intelligence are better able to cultivate productive working relationships (Rosete \& Ciarrochi, 2005). In addition, Rosete (2007) found that higher emotionally intelligent managers were rated higher on business performance by supervisors. Cote and Minders (2006) also found that employees scoring one standard deviation below the mean on an intelligence test exhibited improved performance and citizenship behaviors if they had higher emotional intelligence. So, while emotional intelligence is still a relatively new construct, an increasing number of studies are looking at the role it may play in organizations, particularly how it relates to performance (O’Boyle, Humphrey, Pollack, Hawver, \& Story, 2011) and team effectiveness (Farh, Seo, \& Tesluk, 2012).

\section{Psychological Safety}

Psychological safety is defined as a shared belief by members of a team that the team is safe for interpersonal risk taking (Edmondson, 1999). Interpersonal risk taking involves activities occurring within the team in which there is a risk of rejection or loss of face, such as admitting to an error or making a novel suggestion. Psychological safety has been shown to be integral to team success, especially when the team's focus is on learning, innovation, and creativity (Nembhard \& Edmondson, 2006). Early studies (Edmondson, 1996, 1999) of psychological safety in healthcare teams revealed that members of psychologically safe teams were more likely to discuss and report errors, because employees felt safe doing so, and that those teams were better able to learn from mistakes and prevent their recurrence. The result was that psychologically-safe teams had higher levels of learning, which led to higher levels of team performance. That is, those learning behaviors that are supported by a psychologically-safe environment enable the team to function at a higher level. More recent studies have supported these initial 
findings (Nembhard \& Edmondson, 2006) and found additional outcomes of psychological safety in work teams including engagement in quality improvement efforts (Carmeli \& Gittell, 2009).

Studies of the psychological safety construct have demonstrated that member's perceptions of psychological safety are negatively impacted by demographic factors, such as status differences within the work group (Edmondson, 1999; Nembhard \& Edmondson, 2006). However the effects of these factors may be offset by intentional behaviors by leaders to encourage inclusion in the group. Psychological safety encourages learning in work teams because team members feel comfortable questioning current methods in order to improve them, and examining problems and mistakes in order to correct them. It additionally encourages innovation because team members feel comfortable presenting "risky" ideas and suggestions without fear of criticism (Baer \& Frese, 2003). It is therefore important for teams focused on learning and/or innovation goals to maintain a psychologically-safe environment. Recent research on psychological safety has therefore been concerned with understanding the team characteristics that facilitate member perceptions of psychological safety.

\section{Collective Induction}

We expect that the emotional intelligence of team members is likely to relate to psychological safety because low levels of emotional intelligence on the team may result in an inability of the team to process and deal with emotional conflict. Conflict, in turn, will reduce perceptions of psychological safety. To develop the rationale for our premises, we utilize Laughlin's (1999) collective induction framework. Laughlin proposed that a specific set of conditions must occur in order for groups to make decisions or solve problems as a collective. According to the collective induction framework for group problem solving, in order for a group to demonstrate a correct response to a problem, four conditions must be met: 1) the group must establish consensus on the conceptual system, 2) the group must have sufficient information, 3) all members must be able to recognize a correct response if presented and 4) at least one member of the group must have the ability, motivation and time to demonstrate the correct response to the rest of the group (Laughlin, 1999). We use this framework to analyze how individual team members' strengths and weaknesses related to emotional intelligence may interact to impact the group's ability to work through emotional problems (i.e. conflict) in the group, which we expect will in turn relate to perceptions of psychological safety.

\section{Hypotheses}

According to the collective induction framework, at least one group member must have sufficient ability, motivation and time to demonstrate correct responses to the group. The beginning of this process is to actually recognize that there is a problem; someone in the group must detect the emotional issue. Applying this to our model of emotional intelligence, if there is an emotional issue (e.g., conflict) in the group, at least one individual must have the emotional perception ability in order to recognize emotional information being transmitted in the group process and must be motivated to share their perception of the problem (Sterner 1966). If a group has no members who possess adequate emotional perception skills, the group will likely suffer from conflict resulting from a failure to recognize emotional signals before the conflict intensifies. This suggests that groups that do not have a member capable of accurately perceiving the emotions of the group's members will be more prone to escalating emotional conflicts, and will therefore experience lower levels of psychological safety.

Hypothesis 1: Member perceptions of psychological safety will be lower in teams in which all members' score are low on the emotional perception dimension.

It is not sufficient, however, for one person to simply perceive the problem. According to the collective induction framework, at least one or more potential solutions to the problem must be presented and explored by the group in order for the group to successfully function. Applying this to emotional 
intelligence, the potential solutions will come from the emotional management branch of the emotional intelligence skill set. Therefore, at least one person in the group must be skilled in the management of emotions in order to develop options for dealing with emotional problems within the group.

\section{Hypothesis 2: Member perceptions of psychological safety will be lower in teams in which all members' score high on the emotional management dimension.}

Another component of the collective induction framework states that the rest of the team must be able to understand and implement a proposed solution. The emotional management dimension concerns one's ability to deal with and, if necessary regulate emotions. Persons with difficulty regulating their own emotional responses may come to be viewed as a "loose cannon" in the team. The uncertainty regarding how this individual may respond to feedback or criticism is expected to negatively impact perceptions of psychological safety in the group. If all team members do not possess a sufficient level of emotional understanding, some members may not be able to contribute to the proposed solutions since they do not understand how the group actions will help with the emotional situation. If they cannot understand why they are performing the actions suggested by the emotional leader of the team, they may choose to not perform them or perform them poorly, which will undermine the solution at hand. The level of emotional understanding for all group members does not have to be as high since all group members are not creating the emotional situation solution as a whole, but rather implementing that solution. Thus the level of emotional understanding for all members has a lower threshold than that for the emotional manager and emotional perceiver.

Hypothesis 3: Member perceptions of psychological safety will be lower for teams in which one or more members have lower scores on the emotional understanding dimension.

Finally each member of the group must possess the skills required to implement a proposed solution. Applying this to emotional intelligence, each member of the group must have a minimum level of emotional facilitation skills in order to deal with the conflict. Emotional facilitation is the ability to utilize emotional information to facilitate thought. If all team members do not possess a sufficient level of emotional facilitation, some members may not be able to correctly implement the proposed solution since they do not have sufficient skills. The level of emotional facilitation for does not have to be as high since the group members are not creating the emotional situation solution as a whole, but rather implementing that solution. Thus the level of emotional facilitation has a lower threshold than that for the emotional manager and emotional perceiver.

\section{Hypothesis 4: Member perceptions of psychological safety will be lower for teams in which one or more members have lower scores on the emotional facilitation dimension.}

\section{Method}

\section{Sample}

Five hundred and thirty seven junior level business students and sophomore level engineering students from a Mid-Atlantic university participated as subjects; the subjects received course credit for their participation. The median age for the students was 20 years old with an average of 20.2 years old with 41.1 percent of the sample female. There subjects were $88.6 \%$ white, $3.2 \%$ African American, $5.2 \%$ Asian American, and 2.5\% Hispanic. The students were formed into groups of three (36 groups), five (3 groups), or six students (69 groups) in a total of 108 teams. The business student teams are required to work together throughout the semester to produce assignments and a final capstone project for each of the four business areas (finance, management, marketing, and operations). The engineering students worked in teams on a semester long strategic business simulation and a research project. 
Table 1

Means, standard deviations and correlations of variables

\begin{tabular}{|c|c|c|c|c|c|c|c|}
\hline & Mean & $\begin{array}{l}\text { Standard } \\
\text { deviation }\end{array}$ & $\begin{array}{c}\text { Psychological } \\
\text { Safety }\end{array}$ & $\begin{array}{l}\text { Emotional } \\
\text { Perception }\end{array}$ & $\begin{array}{c}\text { Emotional } \\
\text { Facilitation }\end{array}$ & $\begin{array}{c}\text { Emotional } \\
\text { Understanding }\end{array}$ & $\begin{array}{c}\text { Emotional } \\
\text { Management }\end{array}$ \\
\hline $\begin{array}{l}1 \text { Psychological } \\
\text { Safety }\end{array}$ & 3.85 & 0.571 & & & & & \\
\hline $\begin{array}{r}\text { 2. Emotional } \\
\text { Perception }\end{array}$ & 97.89 & 14.22 & $0.174 * *$ & & & & \\
\hline $\begin{array}{l}\text { 3. Emotional } \\
\text { Facilitation }\end{array}$ & 108.24 & 22.49 & 0.093 & $0.423 * *$ & & & \\
\hline $\begin{array}{l}\text { 4. Emotional } \\
\text { Understanding }\end{array}$ & 115.63 & 17.03 & 0.061 & $0.276^{* *}$ & $0.306 * *$ & & \\
\hline $\begin{array}{l}\text { 5. Emotional } \\
\text { Management }\end{array}$ & 112.97 & 20.64 & $0.097 *$ & $0.334 * *$ & $0.426 * *$ & $0.340 * *$ & \\
\hline $\begin{array}{l}\text { 6. Emotional } \\
\text { Intelligence }\end{array}$ & 106.10 & 18.23 & $0.163^{*}$ & $0.787 * *$ & $0.671 * *$ & $0.678 * *$ & $0.844 * *$ \\
\hline
\end{tabular}

Significance levels: $* * \mathrm{p}<0.01, * \mathrm{p}<0.05$

\section{Independent Variables}

As part of the management and engineering lectures in the courses, the concept of emotional intelligence was introduced in discussion on individual characteristics. The students were then offered the opportunity for learning their level of emotional intelligence by taking the Mayer-Salovey- Caruso Emotional Intelligence Test (MSCEIT). This test is taken online and consist of 141 items for four different scales reporting the result of the four branches of emotional intelligence perceiving emotions, facilitating thought, understanding emotions, and managing emotions (EP, EF, EU, and EM respectively), as well as an overall emotional intelligence score. The students were provided with a customized report of their individual results with explanations of the meanings and ways of improving scores in a given area. Table 1 displays the means, standard deviations and correlations of all of the variables used in this study.

The MSCEIT has been validated in several studies and in scoring our results we used the expert scoring that is one of the two available options. In expert scoring, the individual results are compared against "the consensus of 21 international emotion experts" (Mayer, Salovey, \& Caruso, 2002: 20). The second scoring option; using consensus in a database of over 5000 takers of the MSCEIT, was not used. In their table 6.1, Mayer, Salovey, \& Caruso (2002: 35) report the reliability of the MSCEIT branch scores as split-half reliabilities for expert scoring of 0.90 (EP), 0.76 (EF), 0.77 (EU), and 0.81 (EM); overall EI has a reliability of 0.91 . Split-half reliabilities are used due to item heterogeneity at the branch and overall level.

To create the groups value used in this study, the minimum and maximum values for each of the four branches of were calculated for each project group. Using these values we could determine when all group members were above a given level of a measure by categorizing groups with the minimum of a branch shore being above a threshold. For example, to determine which groups that had all members with Emotional Understanding scores above the sample mean, we would create a dummy variable that was a one when the minimum value for EU in the group was above the sample mean, and a zero for the remaining groups. This value was then assigned to that group. To determine which groups had at least one member with an Emotional Management score above the mean, we would create a dummy variable that was one when the maximum value for EM was above the mean. In this way we could create categories for different groups based on their composition of individual branch score of emotional intelligence.

Using this methodology four dummy variables were created for each group that indicated that the group had the characteristics (1) of at least one member above the sample mean in Emotional Perception, 
(2) of at least one member above the sample mean in Emotional Management, (3) of all members above one standard deviation below the mean in Emotional Facilitating, and (4) of all members above one standard deviation below the mean in Emotional Understanding. This produced 16 possible categories for a group when the four dummy variables are combined.

To form groups that would be more meaningful with our theory development testing, we combined several groups categories as follows. First we combine any groups that did not meet the conditions that at least one member was above the average in Emotional Perception. This new category collapsed 8 of our 16 theoretical categories into one; the resulting new category is one where there is not a strong emotional perceiver in the group.

The remaining combinations all had at least one team member with Emotional Perception above the sample mean. Of these eight remaining categories we combined the groups that did not have at least one member above average in Emotional Management; this combined four more categories into one that had an emotional perceiver but no emotional manager. The four remaining combinations of EP, EF, EU, and EM were then left to stand alone and thus we had six categories of groups to test in a univariate ANOVA with Psychological safety as the dependent variable. These six categories per the hypothesis should have unequal means and further we can predict the order based upon our development above of the means (shown in table 1).

\section{Dependent Variables}

Whenever possible, we used standard accepted scales that were validated in previous studies to measure the constructs in our study. These items were administrated as part of a survey given to the students near the end of the semester. Items were randomized on the survey and several items were reversed coded.

\section{Psychological Safety}

To measure psychological safety we used the 8 item scale based upon Edmondson's (1999) team psychological safety scale (alpha $=0.79$ ). This scale includes such items as "I felt free to disagree with members of the group" and "No one in this team would deliberately act in a way that undermines my efforts." Item responses were on a 5-point scale that ranged from strongly disagree to strongly agree.

\section{Results}

Table 2 displays the resulting categories used in testing ordered (as shown on the far right) from predicted low to high psychological safety. Mean values for the sample data are shown on the far right.

A one-way ANOVA was conducted to evaluate the relationship between minimum individual and group levels of the branches of emotional intelligence using the categories as described in the method section above. Results on this six category model detected significant differences in the means of each category $\left(\mathrm{F}=2.317, \mathrm{dof}_{1}=5, \mathrm{dof}_{2}=433, \mathrm{p}=0.043\right)$. The differences in means were slight (EP and $\mathrm{EP}$ above average mean was 3.914 and the rest had a mean of 3.746 for psychological safety). 
Table 2

Categories created using group level variable of the emotional intelligence branches.

\begin{tabular}{|c|c|c|c|c|c|c|}
\hline $\begin{array}{l}\text { Mean of } \\
\text { Psychological } \\
\text { Safety }\end{array}$ & $\begin{array}{c}\text { Category } \\
\text { Designation }\end{array}$ & $\begin{array}{l}\text { EP > } \\
\text { Sample } \\
\text { Mean }\end{array}$ & $\begin{array}{l}\text { EM > } \\
\text { Sample } \\
\text { Mean }\end{array}$ & $\begin{array}{c}\text { All EF }>\text { Sample } \\
\text { Mean of EF } \\
\text { minus one } \\
\text { standard } \\
\text { deviation }\end{array}$ & $\begin{array}{c}\text { All EU > } \\
\text { Sample Mean } \\
\text { of EF minus } \\
\text { one standard } \\
\text { deviation }\end{array}$ & $\begin{array}{l}\text { Predicted Order of } \\
\text { Psychological } \\
\text { Safety Mean }\end{array}$ \\
\hline 3.692 & 0 & 0 & - & - & - & \multirow{6}{*}{$\begin{array}{c}\text { Lowest } \\
\text { Psychological } \\
\text { Safety } \\
\\
\\
\text { Greatest } \\
\text { Psychological } \\
\text { Safety }\end{array}$} \\
\hline 3.809 & 1 & 1 & 0 & - & - & \\
\hline 3.900 & 2 & 1 & 1 & 0 & 0 & \\
\hline 3.936 & 3 & 1 & 1 & 1 & 0 & \\
\hline 3.956 & 4 & 1 & 1 & 0 & 1 & \\
\hline 3.909 & 5 & 1 & 1 & 1 & 1 & \\
\hline
\end{tabular}

Note: A one (1) in the column indicates that the value was above the threshold indicated at the top of the column. A zero (0) indicates that the group did not meet this threshold. A dash (-) indicates either that any value will be valid for this category.

\section{Discussion}

\section{Summary and Theoretical Issues}

This study explored the interaction between team member's emotional intelligence and the impact on team member perceptions of psychological safety. This study found some support for a model of emotional intelligence in work teams that suggests that teams need at least one member with a minimum level of skill in the emotional perception dimension and at least one member with a minimum level of skill in the emotional management dimension. These results suggest that one member of the team must recognize the "solution" to emotional issues. This is similar to Steiner's (1966) model of productivity where actual productivity $=$ potential productivity - motivation losses - coordination losses. In other words, team members must not only recognize emotional issues in the team, but they must know how to solve the issue, be motivated to intervene and have the opportunity to do so. Results also suggest that all members of the team must have a minimal level of skill in the emotional facilitation and understanding dimensions. Using the collectiveto the ability of organizations to more effectively build work teams with complementary emotional intelligence skills to reduce coordination loss due to the improper handling of emotional events, which will in turn, improve the efficiency of modern organizations. This model of team building may be especially beneficial for work teams dealing with emotionally charged events or in emotionally taxing environments where emotional perception and management are important to the team process. 


\section{References}

Baer, M., \& Frese, M. (2003). Innovation is not enough: Climates for initiative and psychological safety, process innovations, and firm performance. Journal of Organizational Behavior, 24, 45-68.

Carmeli, A., \& Gittell, J. H. (2009). High-Quality relationships, psychological safety, and learning from failures in work organizations. Journal of Organizational Behavior, 30, 709-729.

Cote', S., \& Miners, C. T. H. (2006). Emotional intelligence, cognitive intelligence and job performance. Administrative Science Quarterly, 51, 1-28.

Edmondson, A. (1996). Learning From Mistakes Is Easier Said Than Done: Group and organizational influences on the detection and correction of human error. Journal of Applied Behavioral Science, $32(1), 5-28$.

Edmondson, A. (1999). Psychological Safety and Learning Behavior in Work Teams. Administrative Science Quarterly, 44, 350-383.

Farh, C., Seo, M., Tesluk, P. (2012). Emotional Intelligence, Teamwork Effectiveness, and Job Performance: The moderating role of job context. Journal of Applied Psychology, 97, 890-900.

Gladstein, D. (1984). Groups in context: A model of task group effectiveness. Administrative Science Quarterly, 29, 499-517.

Guzzo, R., Shea, G. (1992). Group performance and intergroup relations in organizations. In M. D. Dunnette \& L.H. Hough (Eds.), Handbook of Industrial and organizational psychology, Volume 3, (2 $2^{\text {nd }}$ ed., pp. 269-313). Palo Alto, CA: Consulting Psychologists Press.

Harper, S. R., A Model of Emotional Intelligence in the Workplace, Presented at the Annual Conference of Academy of Management, New Orleans, LA 6-11 August 2004.

Hackman, J. (1987). The design of work teams. In Handbook of Organizational Behavior (pp. 315-342). Englewood Cliffs, NJ: Prentice Hall.

Laughlin, P. (1999). Collective Induction: Twelve postulates. Organizational Behavior and Human Decision Processes, 80(1), 50-69.

Mayer, J. \& Salovey, P. (1993). The Intelligence of Emotional Intelligence? Intelligence, 17, 433-442.

Mayer, J. \& Salovey, P. (1997). What is emotional intelligence? In P. Salovey \& D. Sluyter (Eds.), Emotional development and emotional intelligence: Implications for educators (pp. 3-31). New York: Basic Books.

Mayer, J., Salovey, P., \& Caruso, D. (2002). Mayer-Salovey-Caruso Emotional Intelligence Test (MSCEIT); User's Manual. Toronto: Multi-Health Systems, Inc.

McEnrue, M. Groves, K., \& Shen, W. (2010). Emotional Intelligence Training: Evidence regarding its efficacy for developing leaders. Leadership Review, 10, 3 - 26.

McGrath, J. (1964). Social Psychology: A brief introduction. New York: Holt, Rinehart \& Winston.

Nembhard, I., \& Edmondson, A. (2006). Making it safe: The effects of leader inclusiveness and professional status on psychological safety and improvement efforts in health care teams. Journal of Organizational Behavior, 27, 941-966.

O’Boyle, E. Humphrey, R., Pollack, J., Hawver, T., \& Story, P. (2011). The Relation Between Emotional Intelligence and Job Performance: A meta-analysis. Journal of Organizational Behavior, 32, 788818.

Pelled, L, Eisenhardt, K., \& Xin, K. (1999). Exploring the Black Box: An analysis of work group diversity, conflict, and performance. Administrative Science Quarterly, 44, 1-28.

Rosete, D. (2007). Does emotional intelligence play an important role in leadership effectiveness? Unpublished doctoral dissertation, University of Wollongong, Wollongong, New South Wales, Australia.

Rosete, D., \& Ciarrochi, J. (2005). Emotional intelligence and its relationship to workplace performance of leadership effectiveness. Leadership \& Organization Development Journal, 26, 388-399.

Steiner, I. (1966). Models for inferring relationships between group size and potential group productivity. Behavioral Science, 11, 273-283. 